\title{
PENILAIAN PARAMETER ECOFISHINGPORT PADA PELABUHAN PERIKANAN SAMUDERA NIZAM ZACHMAN JAKARTA
}

\section{ASSESSMENT OF ECOFISHINGPORT PARAMETERS AT JAKARTA NIZAM ZACHMAN OCEANIC FISHINGPORT}

\author{
Retno Muninggar, Ernani Lubis, Budhi Hascaryo Iskandar \\ Departemen Pemanfaatan Sumberdaya Perikanan, \\ Fakultas Perikanan dan Ilmu Kelautan, IPB University \\ Korespondensi: muninggar@apps.ipb.ac.id
}

\begin{abstract}
Nizam Zachman Oceanic Fishing Port of Jakarta (PPSNZJ) is the largest fishing port in Indonesia, as the center of industry and fishery product exports. On the other hand, PPSNZJ has various environmental problems such as water quality degradation and waste handling. The problem solved by the ecofishingport parameter approach (environmentally friendly port). The objective of the research is to assess the existing conditions of the PPSNZJ based on the ecofishingport parameters by determining the ecofishingport index. The research was carried out from January to March 2017. The data collection used a purposive and accidental sampling method. Data analysis using standard ecofishingport parameters which consisting of the physical environment aspects, socio-economy, fisheries catch, institutional and monitoring. The results showed that score was 0,63 for the environmental aspect, 0,27 for the socio-economic aspect, 0,40 for the fisheries catch aspect, and 0,50 for the institutional and monioring aspect. The analysis of ecofishingport index showed that PPSNZJ obtained an index value of 1.77 (toward ecofishingport).
\end{abstract}

Keywords: ecofishingport, environmental management, port, PPSNZJ

\begin{abstract}
ABSTRAK
Pelabuhan Perikanan Samudera Nizam Zachman Jakarta (PPSNZJ) merupakan pelabuhan perikanan terbesar di Indonesia, sebagai pusat industri dan ekspor hasil perikanan. Namun di sisi lain, PPSNZJ menghadapi berbagai permasalahan lingkungan seperti penurunan kualitas air dan pengolahan limbah cair. Permasalahan lingkungan pelabuhan dapat diatasi melalui penerapan konsep ecofisbingport (pelabuhan perikanan berwawasan lingkungan). Tujuan penelitian adalah melakukan penilaian terhadap kondisi eksisting PPSNZJ berdasarkan parameter ecofishingport. Penelitian lapang dilaksanakan pada bulan Januari-Maret 2017. Metode pengumpulan data menggunakan pendekatan purposive dan accidental sampling. Metode analisis data menggunakan standar parameter ecofishingport yang terdiri dari aspek lingkungan fisik, sosial ekonomi, hasil tangkapan, kelembagaan dan pengawasan. Hasil penelitian menunjukkan skor aspek lingkungan 0,63 , skor aspek sosial ekonomi 0,27 , skor aspek hasil tangkapan 0,40 , skor aspek kelembagaan dan pengawasan 0,50. Analisis indeks ecofishingport menunjukkan PPSNZJ mendapat skor 1,77 (PPSNZJ perlu peningkatan menuju kriteria ecofishingport).
\end{abstract}

Kata kunci: ecofishingport, pengelolaan lingkungan, pelabuhan, PPSNZJ 


\section{PENDAHULUAN}

Konsep pengelolaan pelabuhan berwawasan lingkungan atau ecoport, merupakan konsep pengelolaan dengan menerapkan prinsip-prinsip pembangunan berkelanjutan yang mengintegrasikan dimensi sosial, ekonomi, dan lingkungan secara seimbang (European Sea Port Organization 2012; OECD 2003). Konsep ecoport pada pelabuhan perikanan dikenal dengan istilah ecofishingport sebagaimana tercantum dalam Rencana Induk Pelabuhan Perikanan Nasional (RIPPN) (Kementerian Kelautan dan Perikanan 2018). Pada kebijakan tersebut dijelaskan bahwa pelabuhan perikananyangtelahmenyediakan fasilitas dasar, pengembangannya diarahkan pada penerapan prinsip ecofishingport dalam operasional pelabuhan perikanan. Berdasarkan kajian FDA dan KKP (2013), parameter standar ecofishingport terdiri dari aspek lingkungan fisik (kualitas perairan, pengolahan sampah padat dan limbah cair, ketersediaan air bersih), aspek sosial ekonomi (pendapatan masyarakat, tenaga kerja, dan persepsi pengguna), aspek hasil tangkapan (ekspor perikanan dan kualitas hasil tangkapan), serta aspek kelembagaan dan pengawasan. Di sisi lain, upaya pengendalian lingkungan merupakan salah satu fungsi pelabuhan perikanan sebagaimana diamanatkan dalam pasal 41 ayat (1) Undang-undang Nomor 45 Tahun 2009 tentang perubahan atas Undangundang Nomor 31 Tahun 2004 tentang Perikanan.

$\begin{array}{rrr}\text { Pelabuhan Perikanan } & \text { Samudera } \\ \text { Nizam Zachman Jakarta } & \text { (PPSNZJ) }\end{array}$
merupakan pelabuhan perikanan terbesar di Indonesia. PPSNZJ sebagai pusat industri dan ekspor perikanan serta didukung oleh kelengkapan fasilitas dan sarana yang memadai menjadi pelabuhan yang memiliki peluang besar dalam pelaksanaan standar ecofishingport. Peluang tersebut didukung pula oleh data volume ekspor produk perikanan PPSNZJ ke negara Uni Eropa dan negara-negara tujuan ekspor lain seperti USA dan Jepang yang cukup besar. Data volume distribusi ekspor PPSNZJ tahun 2016 mencapai 75 juta ton naik sebesar 25\% dari tahun sebelumnya yang hanya 60 juta ton. Komoditas ekspor terbesar adalah Frozen Squid; Frozen Tuna Fish; Frozen Skipjack dan Mackerel. Lima negara tujuan ekspor terbesar tahun 2016 antara lain China, Uni Eropa, dan Amerika Serikat (PPSNZJ 2017).
Hasil tangkapan di PPSNZJ didominasi oleh hasil tangkapan dengan Mutu I dan II yaitu ikan dengan kualitas sangat baik dan baik.

Di sisi lain, PPSNZJ memiliki berbagai permasalahan terkait pengelolaan lingkungan. Beberapa penelitian sebelumnya menunjukkan bahwa terjadi penurunan kualitas perairan di PPSNZJ (Hakim 2013; Muninggar et al. 2017), dan penurunan kapasitas Instalasi Pengolahan Limbah (Perdana 2017). PPSNZJ hingga saat ini belum melaksanakan pengelolaan lingkungan secara optimal sebagaimana hasil kajian Supriyanto (2013) dan Muninggar et al. (2016). Berbagai permasalahan lingkungan tersebut jika tidak segera ditangani, dapat saja berdampak pada kualitas hasil tangkapan dan image pelabuhan karena kurangnya sanitasi dan hygenitas. Di sisi lain, limbah industri yang terdapat di PPSNJZ jika tidak dikelola dengan baik pada beberapa tahun ke depan akan menyebabkan pencemaran laut dan mengganggu keseimbangan kehidupan biota di perairan.

Permasalahan lingkungan di PPSNZJ membutuhkan upaya pengelolaan lingkungan melalui penerapan prinsip ecofishingport. Dikarenakan PPSNZJ belum menerapkan konsep tersebut, maka perlu dilakukan penilaian kondisi eksisting pengelolaan lingkungan PPSNZJ berdasarkan parameter ecofishingport. Penerapan parameter ecofishingport di PPSNZJ menjadi sebuah kebutuhan karena adanya tuntutan keamanan pangan oleh negara-negara pengimpor. Keamanan pangan seperti bebasnya bakteri dan logam berat pada hasil tangkapan yang diekspor akan diraih jika aspek ketersediaan air bersih (yang menjadi salah satu parameter ecofishingport) dapat dipenuhi. Tujuan penelitian ini adalah melakukan penilaian parameter ecofishingport untuk PPSNZJ. Hasil kajian diharapkan dapat bermanfaat bagi pengelola PPSNZJ dalam menyusun kebijakan pengelolaan lingkungan berdasarkan parameter ecofishingport.

\section{METODE PENELITIAN}

Penelitian lapang dilaksanakan pada bulan Januari-Maret 2017, di Pelabuhan Perikanan Samudera Nizam Zachman Jakarta (PPSNZJ), kecamatan Penjaringan, Jakarta Utara. Penelitian menggunakan pendekatan studi kasus 
dengan satuan kasus adalah pengelolaan lingkungan PPSNZJ. Pengumpulan data dilakukan melalui kegiatan wawancara dan pengamatan lapang. Wawancara dilakukan kepada para responden yang terdiri dari pengelola pelabuhan dan pengguna pelabuhan. Responden dari kalangan pengelola dipilih secara purposive yang dikategorikan sebagai key informan dan memiliki keahlian terkait tujuan penelitian. Jumlah responden adalah 10 orang yang terdiri dari: 1 orang Kepala PPSNZJ, 1 orang kepala bidang operasional, 4 orang staf bidang operasional dan lingkungan, serta 4 orang staf ahli Perum Perindo (Perusahaan Umum Perikanan Indonesia) cabang Jakarta. Pemilihan 10 orang responden dilakukan dengan pendekatan purposive melalui pertimbangan karakteristik sampel yang homogen dan keahlian yang dimiliki para responden. Penentuan jumlah 10 orang dilakukan saat penelitian berlangsung, karena mempertimbangkan jumlah key informan yang dapat ditemui dan bersedia diwawancarai. Sedangkan responden dari kalangan pengguna terdiri dari nelayan, pemilik kapal, pegawai, dan konsumen yang datang ke PPSNZJ. Penarikan sampel dilakukan melalui pendekatan accidental sampling dengan total responden adalah 40 orang. Metode accidental sampling dilakukan dengan menetapkan kategori responden menjadi 5 kategori yaitu nelayan, pemilik kapal, pegawai pelabuhan, pegawai non pelabuhan dan konsumen. Setiap kategori ditentukan 8-10 orang yang akan dijadikan responden, dengan teknis pengambilan sampel secara accidental (yang kebetulan bertemu dengan peneliti).

Data primer diperoleh melalui wawancara mendalam yang dilakukan pada responden terpilih. Wawancara mendalam dibangun dengan landasan literatur yang terkait dengan parameterparameter ecofishingport. Parameter tersebut meliputi: aspek lingkungan fisik, sosial ekonomi, kelembagaan pengelola; komoditas perikanan dan pengawasan. Data sekunder berupa regulasi terkait peraturan pengelolaan pelabuhan perikanan dan lingkungan.

Penelitian ini menggunakan analisis data parameter ecofishingport yang dimodifikasi dari konsep pelabuhan berwawasan lingkungan yang dikembangkan FDA dan KKP (2013) dan Siahaan (2012). Selanjutnya digunakan metode skoring untuk penentuan parameter dan indeks ecofishingport. Parameter, rumusan standar, teknik pengumpulan data, dan skala penilaian tertera pada Tabel 1. Metode penentuan indeks ecofishingport berdasarkan hasil skoring tersedia pada Tabel 2.

Tabel 1. Skala penilaian parameter ecofishingport

\begin{tabular}{|c|c|c|c|c|}
\hline No & Parameter & $\begin{array}{c}\text { Rumusan Standar dan } \\
\text { pengumpulan data }\end{array}$ & $\begin{array}{c}\text { Dasar } \\
\text { Pelaksanaan }\end{array}$ & Skala Penilaian \\
\hline 1 & $\begin{array}{l}\text { Kualitas } \\
\text { Perairan } \\
\text { Pelabuhan }\end{array}$ & $\begin{array}{l}\text { - Indeks Pencemar }(P i j) \\
\text { - Pengambilan sampel } \\
\text { air dilakukan di } \\
\text { kolam pelabuhan } \\
\text { PPSNZJ dengan } 5 \\
\text { stasiun pengamatan } \\
\text { dan } 2 \text { x waktu } \\
\text { pengambilan } \\
\text { sampel yaitu musim } \\
\text { peralihan dan musim } \\
\text { kemarau. } \\
\text { - Hasil sampling air } \\
\text { kemudian diuji } \\
\text { di laboratorium } \\
\text { bersertifikasi }\end{array}$ & $\begin{array}{l}\text { Metode Indeks } \\
\text { Pencemar dan } \\
\text { baku mutu air } \\
\text { laut (KemenLH } \\
\text { 2003) }\end{array}$ & 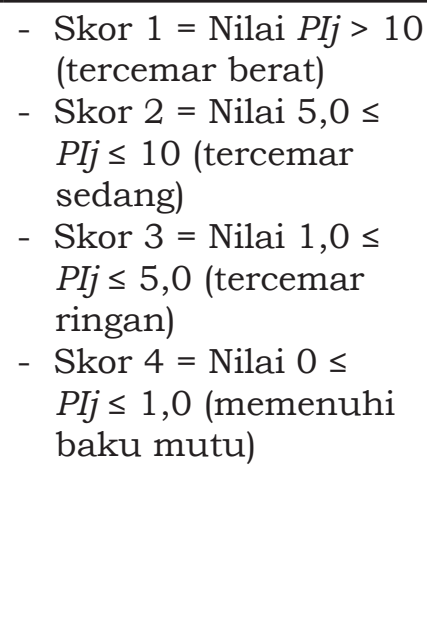 \\
\hline
\end{tabular}




\begin{tabular}{|c|c|c|c|c|}
\hline 2 & $\begin{array}{l}\text { Tingkat } \\
\text { Kebersihan } \\
\text { Lingkungan }\end{array}$ & $\begin{array}{l}\text { - Pengangkutan } \\
\text { sampah dan proses } \\
\text { Reduce, Reuse, dan } \\
\text { Recycle (3R) } \\
\text { - Pengumpulan data } \\
\text { melalui wawancara } \\
\text { dan pengamatan } \\
\text { terhadap proses } \\
\text { pengangkutan } \\
\text { sampah padat di } \\
\text { lingkungan PPSNZJ }\end{array}$ & $\begin{array}{l}\text { PermenLH No } \\
13 \text { tahun } 2012 \\
\text { tentang Pedoman } \\
\text { Pelaksanaan } \\
\text { Reduce, Reuse, } \\
\text { dan Recycle } \\
\text { Melalui Bank } \\
\text { Sampah }\end{array}$ & 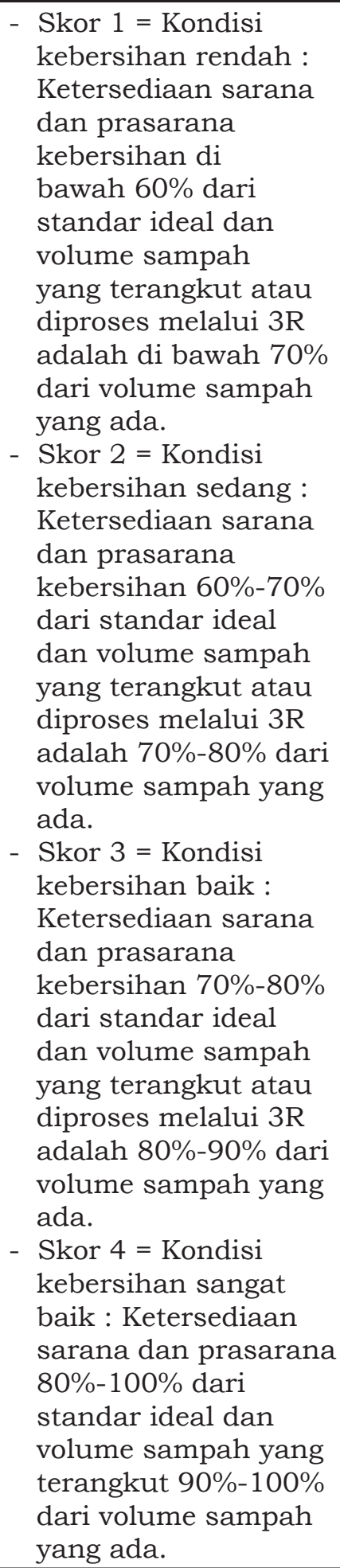 \\
\hline
\end{tabular}




\begin{tabular}{|c|c|c|c|c|}
\hline 3 & $\begin{array}{l}\text { Pengelolaan } \\
\text { Limbah Cair }\end{array}$ & $\begin{array}{l}\text { - Parameter fisik, } \\
\text { kimia dan biologi air } \\
\text { limbah memenuhi } \\
\text { standar baku air } \\
\text { limbah } \\
\text { - Pengumpulan } \\
\text { data melalui } \\
\text { pengamatan lapang } \\
\text { dan wawancara } \\
\text { responden terkait } \\
\text { kondisi IPAL di } \\
\text { PPSNZJ } \\
\text { - Data kualitas air } \\
\text { buangan limbah } \\
\text { didapatkan } \\
\text { berdasarkan data } \\
\text { sekunder yang } \\
\text { dikeluarkan oleh } \\
\text { BPLHD (Badan } \\
\text { Pengelolaan } \\
\text { Lingkungan Hidup } \\
\text { Daerah) DKI Jakarta }\end{array}$ & $\begin{array}{l}\text { Permen LH No } \\
5 \text { Tahun 2014, } \\
\text { Per.Gub DKI No. } \\
69 / 2013 \text { dan } \\
\text { Penggunaan } \\
\text { Instalasi } \\
\text { Pengolahan } \\
\text { Limbah (IPAL) } \\
\text { di pelabuhan } \\
\text { perikanan } \\
\text { (KemenLH, 2014); } \\
\text { (PergubJakarta, } \\
\text { 2013) }\end{array}$ & $\begin{array}{l}\text { - Skor } 1 \text { = Pelabuhan } \\
\text { perikanan tidak } \\
\text { memiliki IPAL } \\
\text { - Skor } 2 \text { = Kondisi } \\
\text { IPAL buruk : mampu } \\
\text { mengolah limbah } \\
\text { <60\% dari kapasitas } \\
\text { terpasangnya } \\
\text { - Skor } 3 \text { = Kondisi IPAL } \\
\text { sedang : mampu } \\
\text { mengolah limbah 60- } \\
\text { 99\% dari kapasitas } \\
\text { terpasangnya } \\
\text { - Skor } 4 \text { = Kondisi } \\
\text { IPAL baik : mampu } \\
\text { mengolah limbah } \\
\text { 100\% dari kapasitas } \\
\text { terpasangnya }\end{array}$ \\
\hline 4 & $\begin{array}{l}\text { Memiliki } \\
\text { Ruang } \\
\text { Terbuka } \\
\text { Hijau (RTH) }\end{array}$ & $\begin{array}{l}\text { - Parameter ruang } \\
\text { terbuka hijau } \\
\text { berdasarkan } \\
\text { pendekatan tata } \\
\text { ruang } 20 \% \text { dari luas } \\
\text { kawasan. } \\
\text { - Pengumpulan data } \\
\text { melalui pengamatan } \\
\text { dan wawancara } \\
\text { responden }\end{array}$ & $\begin{array}{l}\text { UU No } 26 \text { Tahun } \\
2007 \text { tentang } \\
\text { penataan ruang } \\
\text { (UU 2007) }\end{array}$ & $\begin{array}{l}\text { - Skor } 1 \text { = Presentase } \\
\text { ruang terbuka hijau } \\
\text { kurang dari standar } \\
\text { yang ditetapkan oleh } \\
\text { tata ruang } \\
\text { - Skor } 2 \text { = Presentase } \\
\text { ruang terbuka hijau } \\
\text { sama dengan standar } \\
\text { yang ditetapkan oleh } \\
\text { tata ruang } \\
\text { - Skor } 3=\text { Presentase } \\
\text { ruang terbuka hijau } \\
\text { lebih besar daripada } \\
\text { ditetapkan oleh tata } \\
\text { ruang }\end{array}$ \\
\hline 5 & $\begin{array}{l}\text { Ketersediaan } \\
\text { Air Bersih }\end{array}$ & $\begin{array}{l}\text { - Pemenuhan } \\
\text { kebutuhan air bersih } \\
\text { di pelabuhan } \\
\text { - Pengumpulan data } \\
\text { melalui perhitungan } \\
\text { kebutuhan air bersih } \\
\text { dan ketersediaan air } \\
\text { pada water supply } \\
\text { yang dikelola Perum } \\
\text { Perindo dan UPT } \\
\text { PPSNZJ }\end{array}$ & $\begin{array}{l}\text { PermenKes } \\
\text { No } 416 \text { Tahun } \\
1990 \text { tentang } \\
\text { syarat-syarat } \\
\text { dan pengawasan } \\
\text { kualitas air }\end{array}$ & $\begin{array}{l}\text { - } \text { Skor } 1=\text { Suplai air } \\
\text { bersih < kebutuhan } \\
\text { air bersih } \\
\text { - Skor } 2 \text { = Suplai air } \\
\text { bersih = kebutuhan } \\
\text { air bersih } \\
\text { - Skor } 3=\text { Suplai air } \\
\text { bersih > kebutuhan } \\
\text { air bersih }\end{array}$ \\
\hline 6 & $\begin{array}{l}\text { Penyerapan } \\
\text { Tenaga Kerja }\end{array}$ & $\begin{array}{l}\text { Penyerapan tenaga } \\
\text { kerja di pelabuhan } \\
\text { langsung dan tidak } \\
\text { langsung di atas } 20 \%\end{array}$ & $\begin{array}{l}\text { UU No. } 13 \text { tahun } \\
2003 \text { tentang } \\
\text { ketenagakerjaan }\end{array}$ & $\begin{array}{l}\text { - } \text { Skor } 1=\text { PTK }<20 \% \\
\text { dari angkatan kerja } \\
\text { - } \text { Skor } 2=\text { PTK } \geq 20 \% \\
\text { dari angkatan kerja }\end{array}$ \\
\hline
\end{tabular}




\begin{tabular}{|c|c|c|c|c|}
\hline 7 & $\begin{array}{l}\text { Pendapatan } \\
\text { Masyarakat }\end{array}$ & $\begin{array}{l}\text { Rata-rata pendapatan } \\
\text { responden }\end{array}$ & $\begin{array}{l}\text { Upah Minimum } \\
\text { Propinsi DKI } \\
\text { Jakarta }\end{array}$ & $\begin{array}{l}\text { - Skor } 1 \text { = Pendapatan } \\
\text { masyarakat sampel } \\
\text { di bawah UMP } \\
\text { - Skor } 2 \text { = Pendapatan } \\
\text { masyarakat sampel } \\
\text { sesuai UMP } \\
\text { - Skor } 3 \text { = Pendapatan } \\
\text { masyarakat sampel } \\
\text { di atas UMP }\end{array}$ \\
\hline 8 & $\begin{array}{l}\text { Kualitas } \\
\text { Hasil } \\
\text { Tangkapan }\end{array}$ & $\begin{array}{l}\text { Penjaminan mutu } \\
\text { perikanan, penerbitan } \\
\text { HACCP pada industri } \\
\text { perikanan }\end{array}$ & $\begin{array}{l}\text { - PP No } 57 \text { Tahun } \\
2015 \text { tentang } \\
\text { Sistem Jaminan } \\
\text { Mutu dan } \\
\text { Keamanan Hasil } \\
\text { Perikanan serta } \\
\text { Peningkatan } \\
\text { Nilai Tambah } \\
\text { Produk Hasil } \\
\text { Perikanan } \\
\text { - Permen KP } \\
\text { No } 19 \text { Tahun } \\
\text { 2001 tentang } \\
\text { Pengendalian } \\
\text { Sistem Jaminan } \\
\text { Mutu dan } \\
\text { Keamanan Hasil } \\
\text { Perikanan }\end{array}$ & $\begin{array}{l}\text { - Skor } 1=\text { dominasi } \\
\text { ikan hasil tangkapan } \\
\text { dengan kualitas } \\
\text { mutu III } \\
\text { - Skor } 2 \text { = dominasi } \\
\text { ikan hasil tangkapan } \\
\text { dengan kualitas } \\
\text { mutu I dan II }\end{array}$ \\
\hline 9 & $\begin{array}{l}\text { Ekspor } \\
\text { Perikanan }\end{array}$ & $\begin{array}{l}\text { Penerbitan SHTI } \\
\text { (Sertifikat Hasil } \\
\text { Tangkapan Ikan) }\end{array}$ & $\begin{array}{l}\text { Permen KP No } \\
13 \text { Tahun } 2012 \\
\text { tentang Sertifikasi } \\
\text { Hasil Tangkapan } \\
\text { Ikan }\end{array}$ & $\begin{array}{l}\text { - Skor } 1 \text { = Pelabuhan } \\
\text { perikanan belum } \\
\text { menerapkan SHTI } \\
\text { - Skor } 2 \text { = Pelabuhan } \\
\text { perikanan sudah } \\
\text { menerapkan SHTI }\end{array}$ \\
\hline 10 & $\begin{array}{l}\text { Kelembagaan } \\
\text { Pengelola }\end{array}$ & $\begin{array}{l}\text { Berdasarkan ada } \\
\text { tidaknya koordinasi } \\
\text { antar lembaga } \\
\text { khususnya pengelola } \\
\text { PPSNZJ }\end{array}$ & Hasil wawancara & $\begin{array}{l}\text { - Skor } 1 \text { = Tidak } \\
\text { ada koordinasi } \\
\text { antar lembaga } \\
\text { dalam pengelolaan } \\
\text { lingkungan } \\
\text { - Skor } 2 \text { = Ada } \\
\text { koordinasi antar } \\
\text { lembaga namun } \\
\text { masih terbatas } \\
\text { - Skor } 3 \text { = Ada } \\
\text { koordinasi antar } \\
\text { lembaga dan sudah } \\
\text { berjalan dengan baik }\end{array}$ \\
\hline
\end{tabular}




\begin{tabular}{|c|c|c|c|c|}
\hline 11 & $\begin{array}{l}\text { Kepatuhan } \\
\text { pada } \\
\text { Regulasi } \\
\text { Lingkungan }\end{array}$ & $\begin{array}{l}\text { Dokumen lingkungan } \\
\text { diperbarui setiap } 6 \\
\text { (enam) bulan }\end{array}$ & $\begin{array}{l}\text { Kepmen LH no } \\
45 \text { Tahun } 2005 \\
\text { tentang Pedoman } \\
\text { Penyusunan } \\
\text { Laporan } \\
\text { Pelaksanaan } \\
\text { Rencana } \\
\text { Pengelolaan } \\
\text { Lingkungan } \\
\text { Hidup (RKL) } \\
\text { dan Rencana } \\
\text { Pemantauan } \\
\text { Lingkungan } \\
\text { Hidup (RPL). }\end{array}$ & $\begin{array}{l}\text { - Skor } 1=\text { Belum } \\
\text { menjalankan } \\
\text { dokumen RKL/RPL } \\
\text { - Skor } 2=\text { Sudah } \\
\text { menjalankan } \\
\text { dokumen RKL/RPL }\end{array}$ \\
\hline 12 & $\begin{array}{l}\text { Pengawasan } \\
\text { Lingkungan }\end{array}$ & $\begin{array}{l}\text { Pengawasan terhadap } \\
\text { pengelolaan aspek } \\
\text { lingkungan di PPSNZJ } \\
\text { oleh DLHD Provinsi } \\
\text { DKI Jakarta }\end{array}$ & $\begin{array}{l}\text { UU No } 32 \text { Tahun } \\
2009 \text { tentang } \\
\text { Perlindungan } \\
\text { dan Pengelolaan } \\
\text { Lingkungan } \\
\text { Hidup }\end{array}$ & $\begin{array}{l}\text { - Skor } 1 \text { = belum } \\
\text { dilaksanakan } \\
\text { penegakan aturan } \\
\text { melalui sanksi } \\
\text { apapun } \\
\text { - Skor } 2 \text { = penegakan } \\
\text { aturan melalui } \\
\text { sanksi tertulis } \\
\text { - Skor } 3 \text { = penegakan } \\
\text { aturan melalui sanksi } \\
\text { lisan dan tertulis } \\
\end{array}$ \\
\hline
\end{tabular}

Sumber: Data yang telah diolah (2017)

Tabel 2. Penentuan indeks ecofishingport berdasarkan skoring

\begin{tabular}{ccl}
\hline Nilai indeks & Kondisi & \multicolumn{1}{c}{ Keterangan Indeks } \\
\hline $0,0-1,0$ & Kurang & Pelabuhan belum bisa disebut ecofishingport \\
$1,1-2,0$ & Sedang & Perlu peningkatan untuk menuju ecofishingport \\
$2,1-3,0$ & Baik & Pelabuhan sudah dapat disebut ecofishingport \\
\hline
\end{tabular}

Sumber: Siahaan (2012)

\section{HASIL DAN PEMBAHASAN}

Penilaian terhadap kondisi pengelolaan lingkungan PPSNZJ berdasarkan parameter ecofishingport, didapatkan hasil sebagaimana tertera pada Tabel 3.

Hasil penilaian aspek lingkungan fisik terkait dengan kualitas perairan pelabuhan dilakukan menggunakan pendekatan Indeks Pencemaran (Pij). Hasil pengamatan pada 5 stasiun dihasilkan bahwa stasiun 1, 2, 4, dan 5 tercemar ringan dan hanya stasiun 3 yang memenuhi baku mutu air laut. Hal ini senada dengan penelitian Hakim (2013) yang menyatakan bahwa bahwa kondisi perairan kolam pelabuhan PPSNZJ untuk biota laut telah tercemar sedang, kondisi perairan untuk pelabuhan perikanan telah tercemar ringan. Perairan kolam pelabuhan tercemar karena adanya berbagai aktivitas yang dilakukan di kolam pelabuhan seperti aktivitas nelayan kapal perikanan yang sedang tambat labuh, aktivitas MCK awak kapal, pembuangan air ballast kapal, sampah dan minyak dari mesin kapal, aktivitas pembersihan palkah kapal dan sebagainya, akan membawa partikel-partikel seperti bahan organik, sehingga mempengaruhi tingkat kecerahan perairan. Tingginya nilai kekeruhan suatu perairan dapat dipengaruhi oleh bahanbahan tersuspensi dan terlarut, terutama TSS, yang dapat pula menghambat penetrasi cahaya matahari ke kolom air (Effendi 2003). Pengaruh limbah cair yang dihasilkan dari aktivitas perikanan, akan membawa dampak secara fisik, seperti adanya perubahan warna air, bau, kekeruhan, rasa, dan padatan tersuspensi (TSS) (Mukhtasor 2007). 
Tabel 3. Hasil penilaian parameter ecofishingport terhadap PPSNZJ

\begin{tabular}{|c|c|c|c|c|}
\hline \multirow[t]{2}{*}{ No } & \multirow[t]{2}{*}{ Parameter } & $\begin{array}{c}\text { Bobot } \\
\text { Parameter } \\
(\%)\end{array}$ & Skor & \multirow{2}{*}{$\begin{array}{c}\begin{array}{c}\text { Nilai } \\
\text { (bobot } \\
\text { parameter } \mathrm{x} \\
\text { skor) }\end{array} \\
\text { (AxB) }\end{array}$} \\
\hline & & $\mathbf{A}$ & $\mathbf{B}$ & \\
\hline & \multicolumn{4}{|l|}{ I. Lingkungan Fisik } \\
\hline 1 & $\begin{array}{l}\text { Kualitas Perairan } \\
\text { Pelabuhan }\end{array}$ & 0,20 & $\begin{array}{l}\text { Skor }=3 \text { (tercemar } \\
\text { ringan) }\end{array}$ & 0,60 \\
\hline 2 & $\begin{array}{l}\text { Tingkat Kebersihan } \\
\text { Lingkungan }\end{array}$ & 0,15 & $\begin{array}{l}\text { Skor }=2 \text { (kondisi } \\
\text { kebersihan sedang) }\end{array}$ & 0,30 \\
\hline 3 & Pengelolaan Limbah Cair & 0,25 & $\begin{array}{l}\text { Skor }=2 \text { (Kondisi IPAL } \\
\text { sedang) }\end{array}$ & 0,50 \\
\hline 4 & $\begin{array}{l}\text { Memiliki Ruang Terbuka } \\
\text { Hijau (RTH) }\end{array}$ & 0,15 & $\begin{array}{l}\text { Skor = } 1 \text { (RTH kurang } \\
\text { dari standar yang } \\
\text { ditetapkan tata ruang) }\end{array}$ & 0,15 \\
\hline \multirow[t]{3}{*}{5} & Ketersediaan Air Bersih & 0,25 & $\begin{array}{l}\text { Skor }=1 \text { (kebutuhan } \\
\text { air }>\text { suplai air bersih) }\end{array}$ & 0,25 \\
\hline & \multicolumn{3}{|c|}{ Total Nilai Aspek Lingkungan Fisik } & 1,80 \\
\hline & \multicolumn{4}{|c|}{ II. Sosial Ekonomi } \\
\hline 1 & $\begin{array}{l}\text { Penyerapan Tenaga } \\
\text { Kerja }\end{array}$ & 0,65 & $\begin{array}{l}\text { Skor }=2 \text { (Penyerapan } \\
\text { tenaga kerja } \geq 20 \%)\end{array}$ & 1,30 \\
\hline \multirow[t]{3}{*}{2} & Pendapatan Masyarakat & 0,35 & $\begin{array}{l}\text { Skor }=1 \text { (pendapatan } \\
\text { responden sampel di } \\
\text { bawah UMP) }\end{array}$ & 0,35 \\
\hline & \multicolumn{3}{|c|}{ Total Nilai Aspek Sosial Ekonomi } & 1,65 \\
\hline & \multicolumn{4}{|c|}{ III. Hasil Tangkapan } \\
\hline 1 & $\begin{array}{l}\text { Kualitas Hasil } \\
\text { Tangkapan }\end{array}$ & 0,55 & $\begin{array}{l}\text { Skor } 2=\text { dominasi } \\
\text { ikan hasil tangkapan } \\
\text { dengan kualitas mutu } \\
\text { I dan II }\end{array}$ & 1,10 \\
\hline \multirow[t]{3}{*}{2} & Ekspor Perikanan & 0,45 & $\begin{array}{l}\text { Skor = } 2 \text { (penerbitan } \\
\text { SHTI) }\end{array}$ & 0,90 \\
\hline & \multicolumn{3}{|c|}{ Total Nilai Aspek Hasil Tangkapan } & 2,00 \\
\hline & \multicolumn{4}{|c|}{ IV. Kelembagaan dan Pengawasan } \\
\hline 1 & Kelembagaan Pengelola & 0,30 & $\begin{array}{l}\text { Skor=2 (koordinasi } \\
\text { pengelolaan } \\
\text { lingkungan sudah } \\
\text { dijalankan namun } \\
\text { masih terbatas) }\end{array}$ & 0,60 \\
\hline 2 & $\begin{array}{l}\text { Kepatuhan pada } \\
\text { Regulasi Lingkungan }\end{array}$ & 0,35 & $\begin{array}{l}\text { Skor } 1 \text { = Belum } \\
\text { menjalankan } \\
\text { dokumen RKL/RPL }\end{array}$ & 0,35 \\
\hline 3 & Penegakan Hukum & 0,35 & $\begin{array}{l}\text { Skor } 2 \text { = penegakan } \\
\text { aturan melalui sanksi } \\
\text { tertulis }\end{array}$ & 0,70 \\
\hline & Total Nilai Aspek Kelemba & gaan dan Per & gawasan & 1,65 \\
\hline
\end{tabular}

Sumber: Hasil analisis 
Upaya yang sebaiknya dilaksanakan oleh pihak PPSNZJ dalam menjaga kualitas perairan adalah melakukan pemantauan status mutu air secara rutin, membersihkan kolam pelabuhan dengan kapal pengangkut sampah, dan memberikan penyuluhan kepada para nelayan dan pengguna agar tidak membuang sampah di kolam pelabuhan.

Penilaian tingkat kebersihan lingkungan PPSNZJ mendapat skor 2 yaitu kondisi kebersihan sedang. Program penanganan sampah dilakukan melalui pengumpulan sampah dari semua kawasan/ zonasi, kemudian diangkut dengan thowing truck dan dikumpulkan di dump truck untuk diangkut keluar pelabuhan, sebagian sampah juga dibakar dengan incinerator. Upaya pemulihan dampak akibat sampah padat belum dilaksanakan oleh pelabuhan. Upaya pemulihan tersebut dapat dilakukan melalui pengolahan sampah atau limbah (re-used) menjadi sumberdaya alam yang dapat dimanfaatkan kembali (new resource) sehingga efisiensi pemanfaatan sumberdaya alam dapat dilakukan, atau yang dikenal dengan ecoefficiency (Fandeli 2012). Upaya pengurangan sampah dilakukan dengan mengurangi penggunaan plastik, seperti menggunakan tempat minum pribadi, mengurangi penggunaan botol mineral, menyediakan tempat sampah di banyak tempat, melakukan sosialisasi dan edukasi konsep zero waste di sejumlah fasilitas pelabuhan, menerapkan aturan dan sanksi yang tegas terkait kebersihan terhadap pengguna pelabuhan.

Penilaian terhadap parameter pengelolaan limbah cair pada fasilitas IPAL mendapat skor 3 karena kondisi IPAL milik PPSNZJ hanya mampu mengolah limbah 85\% dari kapasitas terpasangnya. Penilaian tersebut berdasarkan hasil pengujian air limbah olahan pada fasilitas IPAL. Data pengujian air limbah buangan IPAL tahun 2015-2017 menunjukkan bahwa sejumlah parameter (TSS, Ammonia, BOD, COD, dan Organik) berada di atas baku mutu air limbah (BPLHD DKI Jakarta 2017). Hal ini disebabkan oleh faktor mesin dan peralatan yang butuh perawatan, kemampuan SDM, serta proses IPAL itu sendiri (Perdana 2017). Kondisi tersebut mengharuskan perbaikan pada mesin IPAL milik PPSNZJ. Parameter yang berada di atas baku mutu harus diperhatikan oleh pihak PPSNZJ karena dapat saja menjadi alasan bagi LSM untuk menuntut PPSNZJ terkait pembuangan limbah ke badan air. Bahan organik seperti
BOD, COD, TSS, dan lemak merupakan bahan organik yang terdapat pada limbah industri perikanan. Bahan organik tersebut jika dibuang ke badan penerima maka akan terjadi pencemaran air pada badan air (Sahubawa 2011). Upaya yang sebaiknya dilakukan pihak PPSNZJ dalam mengolah limbah cair industri adalah dengan melakukan pemeliharaan dan perbaikan IPAL. Untuk menutupi anggaran perawatan IPAL yang cukup besar, pihak pelabuhan sangat tergantung pada kebijakan anggaran dari KKP. Pihak UPT dapat bersinergi dengan Perum Perindo sebagai pemilik lahan untuk mengarahkan para pelaku usaha di kawasan PPSNZJ memiliki IPAL sendiri.

Penilaian terhadap parameter Ruang Terbuka Hijau (RTH) mendapat skor 1 yang menunjukkan bahwa PPSNZJ memiliki RTH kurang dari standar yang ditetapkan tata ruang. Ruang terbuka hijau pada pelabuhan berwawasan lingkungan adalah sebesar $20 \%$ dari luas kawasan pelabuhan (UU No 26 tahun 2007). PPSNZJ hanya memiliki 1\% dari luas kawasan pelabuhan, dimana luas kawasan pelabuhan 71 ha dan luas ruang terbuka hijau hanya $6.500 \mathrm{~m}^{2}$ lebar $5 \mathrm{~m}$ dan panjang $1.300 \mathrm{~m}$. Kondisi penghijauan pelabuhan akan mempengaruhi kualitas udara, estetika, suhu mikro (lokal), dan kenyamanan (Supriyanto 2013). Upaya yang sebaiknya dilakukan oleh pihak PPSNZJ untuk menambah RTH adalah menanam berbagai pohon di sekitar jalan masuk pelabuhan dan beberapa lahan terbuka yang masih kosong.

Penilaian parameter ketersediaan air bersih mendapat skor $=1$ (kebutuhan air>suplai air bersih). Suplai air bersih di PPSNZJ dikelola oleh 4 (empat) perusahaan jasa water supply yaitu PT CNE, TSA, Palyja, dan SWRO. Suplai air bersih di PPSNZJ adalah $4.600 \mathrm{~m}^{3}$ /hari (Pusdatin KKP 2016), sedangkan kebutuhan air bersih berdasarkan data pengguna (kegiatan perbekalan melaut, industri, dan pengguna lain seperti konsumen dan pegawai) adalah $6.623 \mathrm{~m}^{3}$ /hari. Berdasarkan data tersebut, penyediaan air bersih hanya dapat memenuhi $74 \%$ dari kebutuhan air di PPSNZJ. Kondisi suplai air bersih yang kurang dikeluhkan pula oleh pengusaha industri tuna di PPSNZJ sehingga tidak jarang mereka mendatangkan air bersih dari luar untuk menunjang aktivitas produksi (Hutapea et al. 2017). Upaya yang sebaiknya dilakukan pihak PPSNZJ dalam mengendalikan ketersediaan air bersih adalah menambah suplai air bersih 
melalui penerapan teknologi desalinasi air laut (mengubah air laut menjadi air tawar) untuk memenuhi demand air bersih.

Penilaian parameter mendapat skor $=2$ (Penyerapan tenaga kerja $\geq 20 \%)$. Tingkat penyerapan tenaga kerja yang baik di suatu pelabuhan sebesar $20 \%$ dari jumlah angkatan kerja yang ada di kelurahan tempat pelabuhan tersebut ada (Siahaan 2012). Rasio jumlah tenaga kerja di PPSNZJ dan jumlah angkatan kerja di kelurahan Penjaringan Jakarta Utara adalah sebesar $82 \%$ hal ini menunjukkan bahwa tingkat penyerapan tenaga kerja di PPSNZJ sudah baik karena di atas 20\%. Upaya peningkatan jumlah tenaga kerja di PPSNZJ tergantung pada jumlah investasi di pelabuhan. Pihak PPSNZ perlu melakukan berbagai upaya dalam meningkatkan image pelabuhan sebagai pusat bisnis dan mempromosikan PPSNZJ sebagai kawasan strategis dalam pengembangan industri perikanan dan kelautan. Hal tesebut diharapkan dapat menarik minat investor dan pada akhirnya membuka banyak peluang kerja dan bisnis di kawasan PPSNZJ.

Penilaian parameter pendapatan masyarakat mendapat skor 1 (pendapatan responden sampel di bawah UMP). Salah satu indikator untuk mengukur dampak positif keberadaan pelabuhan perikanan adalah kesejahteraan masyarakat yang berada di sekitar pelabuhan perikanan tersebut. Tingkat kesejahteraan dapat diukur melalui tingkat pendapatan masyarakat.

Hasil wawancara dengan responden menunjukkan bahwa 50\% dari responden memiliki pendapatan pada level pendapatan $\geq \mathrm{Rp} 3.100 .000$. Responden yang memiliki pendapatan Rp 1.000.000-3.100.000 sebanyak $43 \%$ danyang memiliki pendapatan Rp 500.000-1.000.000 sebanyak 7\%. Jika dirata-ratakan maka pendapatan responden adalah Rp 2.955.666, nilai tersebut masih berada di bawah UMP DKI Jakarta. Upaya yang dapat dilakukan untuk meningkatkan pendapatan masyarakat di sekitar PPSNZJ sangat erat kaitannya dengan terbukanya peluang kerja dan bisnis di kawasan pelabuhan tersebut. Oleh karena itu, upaya yang dapat dilakukan PPSNZJ adalah menjadikan pelabuhan sebagai pusat bisnis yang dapat menarik investor. Dengan menjadi pelabuhan perikanan yang berwawasan lingkungan diharapkan menjadi nilai tambah dan daya saing bagi PPSNZJ, sehingga peluang investasi makin terbuka.
Penilaian parameter kualitas hasil tangkapan di PPSNZJ mendapatkan skor 2, artinya dominasi ikan hasil tangkapan yang didaratkan memiliki kualitas mutu I dan II (sangat baik dan baik). Volume produksi ikan PPSNZJ yang berasal dari laut pada tahun 2016 adalah 76.540,57 ton. Ikan hasil tangkapan tersebut terdiri dari mutu I (kualitas sangat baik) sebanyak 35.534,87 ton (46\%), mutu II (kualitas baik) sebanyak $39.462,02$ ton $(51 \%)$, dan mutu III (kualitas sedang-buruk) sebanyak 1.538, 68 ton (3\%) berdasarkan data statistik PPSNZJ (2017). Kualitas hasil tangkapan yang didaratkan di PPSNZJ sebagian besar telah mendapatkan penanganan rantai dingin selama di kapal. Sebagian besar kapal telah dilengkapi dengan freezer, namun berdasarkan laporan FDA dan KKP (2013), kapal-kapal di PPSNZJ perlu dilengkapi alat pengatur suhu agar menjaga kestabilan suhu pada palkah mereka. Pihak UPT juga telah melakukan penyuluhan terkait program CPIB (Cara Penanganan Ikan yang Baik) sebagai langkah teknis menjaga kualitas hasil tangkapan. Penilaian parameter ekspor hasil tangkapan mendapatkan skor 2 karena telah menerapkan catch certificate pada produk perikanan yang diimpor ke negara Uni Eropa.

Penilaian parameter kelembagaan mendapatkan skor 2 yaitu koordinasi pengelolaan lingkungan sudah dijalankan namun masih terbatas. Koordinasi antara pengelola PPSNZJ yaitu UPT (Unit Pelaksana Teknis) PPSNZJ dan Perum Perindo masih terbatas pada penyelenggaran kebersihan lingkungan, sedangkan terkait aspek pengelolaan kualiatas air bersih dan perawatan Instalasi Pengelolaan Air Limbah (IPAL) belum dijalankan. Pengelolaan lingkungan kawasan dapat dilakukan secara efektif jika ada sinergi dan kerjasama diantara stakeholder yang ada di PPSNZJ. Koordinasi antara UPT dan Perum sebaiknya tidak terbatas pada aspek K3, namun pada seluruh aspek yang terkait dengan pengelolaan lingkungan seperti pengolahan air bersih, IPAL, pengawasan terhadap lingkungan dan sebagainya.

Penilaian parameter kepatuhan pada regulasi lingkungan mendapat skor 1 yaitu belum menjalankan dokumen RKL/ RPL. Tingkat kepatuhan PPSNZJ terhadap regulasi lingkungan salah satunya adalah dengan kesediaan PPSNZJ memperbarui dokumen RKL/RPL setiap 6 (enam bulan sekali) berdasarkan Kepmen LH no 45 Tahun 
2005. Skor $2=$ penegakan aturan melalui sanksi tertulis, pengawasan terhadap pengelolaan aspek lingkungan di PPSNZJ belum dijalankan oleh pejabat pengawas dalam hal ini DLHD Provinsi DKI Jakarta (UU No 32 tahun 2009) kecuali pada aspek yang terbatas yaitu pemantauan terhadap kualitas air limbah yang dikelola IPAL milik PPSNZJ. Pihak PPSNZJ juga memiliki kewenangan dalam melakukan pengawasan dan pemantauan terhadap kegiatan yang dilakukan para stakeholder. Berdasarkan wawancara kepada pengelola PPSNZJ, selama ini pihaknya telah melakukan upaya pengawasan melalui teguran lisan bagi stakeholder yang melanggar, contohnya teguran kepada ABK dan pemilik kapal yang membuang sampah di kolam pelabuhan. Berdasarkan wawancara kepada pengelola PPSNZJ, selama ini pihaknya telah melakukan upaya pengawasan melalui teguran lisan bagi stakeholder yang melanggar, contohnya teguran kepada ABK dan pemilik kapal yang membuang sampah di kolam pelabuhan.

Berdasarkan hasil skoring pada Tabel 3, kemudian ditetapkan indeks ecofisingport untuk PPSNZJ sebagaimana tertera pada Tabel 4.

$\begin{array}{ccr}\text { Hasil } & \text { pengukuran } & \text { indeks } \\ \text { ecofishingport } & \text { terhadap } & \text { PPSNZJ }\end{array}$ menghasilkan angka indeks 1,77 yang artinya PPSNZJ dalam tahap perlu peningkatan menuju kriteria ecofishingport. Indeks ecoport dibuat untuk melihat sejauh mana PPSNZJ telah berada pada standar ecofishingport. Hasil penilaian parameter ecofishingport menunjukkan bahwa PPSNZJ memiliki peluang besar untuk diterapkannya konsep dalam pengelolaan seluruh aktivitas pelabuhan. Hal ini karena PPSNZJ telah memiliki sejumlah fasilitas yang dibutuhkan dalam standar ecofishingport, seperti instalasi pengolahan limbah, penyediaan air bersih, dan pengelolaan sampah. Namun karena pengelolaan pelabuhan secara umum belum berorientasi lingkungan, maka aspek-aspek yang termasuk dalam parameter ecofishingport belum dikelola dengan baik. Di sisi lain, banyak manfaat yang akan didapatkan oleh pelabuhan jika menerapkan konsep ecofishingport, diantaranya: (1) Pengurangan biaya: melalui pengelolaan sumber daya yang lebih baik (misalnya energi, air) akan menurunkan biaya operasional pelabuhan dan industri; (2) Minimalisasi risiko: melalui pelaksanaan prosedur operasional yang telah ditetapkan; (3) Kepatuhan peraturan: kesadaran akan pelaksanaan regulasi yang lebih baik akan memberi dampak positif bagi pengelolaan pelabuhan; (4) Peningkatan hubungan dengan pemangku kepentingan lokal: akan meningkatkan peluang bisnis dengan masyarakat lokal; (5) Peningkatan hubungan dengan pemangku kepentingan eksternal: meningkatkan kredibilitas dan transparansi; (6) Keunggulan kompetitif: dapat meningkatkan akses pasar dan meningkatkan pangsa pasar (FDA dan KKP 2013).

Penilaian indeks ecoport/ ecofishingport telah dilakukan pada pelabuhan niaga Tanjung Priok, dimana hasilnya hampir sama dengan PPSNZJ yaitu indeks ecoport adalah 1,74 artinya masih perlu peningkatan setiap komponen untuk bisa memenuhi standar ecoport (Siahaan 2012). Standar ecoport melalui penerapan konsep ramah lingkungan dan berteknologi otomasi mulai diterapkan di PT Terminal Teluk Lamong yang merupakan anak perusahaan Pelindo III. Pelabuhan terminal operator yang mengedepankan pelayanan dengan fasilitas yang berteknologi tinggi tersebut mengusung konsep The First Green Port in Indonesia (Ayunda 2016).

Tabel 4. Hasil perhitungan indeks ecofishingport untuk PPSNZJ

\begin{tabular}{lcccc}
\hline & $\begin{array}{c}\text { Lingkungan } \\
\text { Fisik }\end{array}$ & $\begin{array}{c}\text { Sosial } \\
\text { Ekonomi }\end{array}$ & $\begin{array}{c}\text { Hasil } \\
\text { Tangkapan }\end{array}$ & $\begin{array}{c}\text { Kelembagaan dan } \\
\text { Pengawasan }\end{array}$ \\
\hline Bobot & 0,35 & 0,15 & 0,20 & 0,30 \\
Nilai & 1,80 & 1,65 & 2,00 & 1,65 \\
Bobot x Nilai & 0,63 & 0,25 & 0,40 & 0,49 \\
Total & 1,77 & & & \\
\hline
\end{tabular}

Sumber: Hasil analisis 
Sejak tahun 2009, parameter ecoport telah diterapkan di beberapa pelabuhan Uni Eropa yang tergabung dalam European Sea Port Organization/ESPO (Le et al. 2014; Puig et al. 2015). Parameter pelabuhan berwawasan lingkungan juga diterapkan negara-negara yang tergabung dalam American Association of Port Authority (AAPA) melalui parameter greenport. Penerapan standar manajemen lingkungan di pelabuhan negara maju menjadi hal yang utama dalam memenangkan persaingan global dan tanggung jawab mereka terhadap keberlanjutan lingkungan.

\section{KESIMPULAN DAN SARAN}

\section{Kesimpulan}

Penilaian parameter ecofishingport pada PPSNZJ menghasilkan kesimpulan bahwa nilai skor untuk aspek lingkungan 0,63 , aspek sosial ekonomi 0,25, aspek hasil tangkapan 0,40 , dan aspek kelembagaan serta pengawasan 0,49 . Nilai indeks ecofishingport PPSNZJ adalah 1,77 yang artinya PPSNZJ perlu peningkatan menuju kriteria ecofishingport. Upaya yang seharusnya dilakukan oleh PPSNZJ adalah dengan melakukan program peningkatan kualitas lingkungan seperti pemantauan rutin kualitas perairan dan melakukan pengolahan air, limbah serta sampah secara berkelanjutan. Dalam aspek ekonomi, pihak pelabuhan seyogyanya berupaya meningkatkan image PPSNZJ sebagai pusat bisnis dan ekonomi agar peluang investasi semakin besar sehingga memberikan multiplier effect pada pendapatan masyarakat di sekitar PPSNZJ.

\section{Saran}

Saran dari penelitian ini adalah pengelola PPSNZJ sebaiknya mulai mengelola parameter ecofishingport agar pengelolaan pelabuhan berwawasan lingkungan dapat segera terwujud di PPSNZJ.

\section{UCAPAN TERIMA KASIH}

Penelitian ini terlaksana atas pendanaan dari program Hibah Penelitian Disertasi Doktor (PDD) tahun 2017 oleh Kementerian Riset dan Pendidikan Tinggi (sekarang Kemendikbud), ucapan terima kasih juga disampaikan kepada Kepala
Pelabuhan dan seluruh staf PPSNZJ atas support yang diberikan selama penelitian.

\section{DAFTAR PUSTAKA}

Ayunda LD. 2016. Aplikasi Konsep Ecoport di Terminal Teluk Lamong Surabaya. Surabaya: Institut Teknologi 10 November.

[BPLHD] Badan Pengelola Lingkungan Hidup Daerah DKI Jakarta. 2017. Hasil Pengujian Kualitas Air pada Fasilitas Instalasi Pengolahan Limbah (IPAL) PPS Nizam Zachman periode 20152017. Jakarta: BPLHD.

Effendi H. 2003. Telaah Kualitas Air bagi Pengelolaan Sumber Daya dan Lingkungan Perairan. Cetakan Kelima. Yogyakarta: Kanisius.

European Sea Port Organization. 2012. ESPO: Green Guide.

Fandeli C. 2012. Analisis Mengenai Dampak Lingkungan Pembangunan Pelabuhan. Yogyakarta: Gadjah Mada University Press.

[FDA dan KKP] French Development Agency dan Kementerian Kelautan dan Perikanan. 2013. Fishing Eco-Ports Preliminary Report. Jakarta: FDA dan KKP.

Hakim LN. 2013. Pengelolaan Kualitas Lingkungan Perairan Pelabuhan Perikanan Samudera Nizam Zachman Jakarta [Tesis]. Depok: Universitas Indonesia.

Hutapea RYF, Solihin I, Nurani TW. 2017. Peran Pelabuhan Perikanan Samudera Nizam Zachman dalam Mendukung Industri Tuna. Marine Fisheries: Jurnal Teknologi dan Manajemen Perikanan Laut. 8: 187198.

[Kemenkes] Kementerian Kesehatan. 1990. Peraturan Menteri Kesehatan No 416 Tahun 1990 tentang Syaratsyarat dan Pengawasan Kualitas Air. Jakarta: Kemenkes.

[KemenLH] Kementerian Lingkungan Hidup. 2003. Keputusan Menteri Lingkungan Hidup No 115 tahun 2003 tentang Pedoman Penentuan Status Mutu Air. Jakarta: KemenLH.

[KemenLH] Kementerian Lingkungan Hidup. 2005. Keputusan Menteri Lingkungan Hidup No 45 tahun 2005 tentang Pedoman Penyusunan Laporan Pelaksanaan Rencana Pengelolaan Lingkungan Hidup 
(RKL) dan Rencana Pemantauan Lingkungan Hidup (RPL). Jakarta: KemenLH.

[KemenLH] Kementerian Lingkungan Hidup. 2012. Peraturan Menteri Lingkungan Hidup No 13 tahun 2012 tentang Pedoman Pelaksanaan Reduce, Reuse, dan Recycle Melalui Bank Sampah. Jakarta: KemenLH.

[KemenLH] Kementerian Lingkungan Hidup. 2014. Peraturan Menteri Lingkungan Hidup No 5 Tahun 2014 tentang Baku Mutu Air Limbah. Jakarta: KemenLH.

Kementerian Kelautan dan Perikanan. 2001. Peraturan Menteri Kelautan dan Perikanan No 19 Tahun 2001 tentang Pengendalian Sistem Jaminan Mutu dan Keamanan Hasil Perikanan. Jakarta: Kementerian Kelautan dan Perikanan.

Kementerian Kelautan dan Perikanan. 2012. Peraturan Menteri Kelautan dan Perikanan No 13 Tahun 2012 tentang Sertifikasi Hasil Tangkapan Ikan. Jakarta: Kementerian Kelautan dan Perikanan.

Kementerian Kelautan dan Perikanan. 2018. Keputusan Menteri Kelautan dan Perikanan No 6 tahun 2018 tentang Rencana Induk Pelabuhan Perikanan Nasional. Jakarta: Kementerian Kelautan dan Perikanan.

Le XQ, Vu VH, Hens L, Van Heur B. 2014. Stakeholder Perceptions and Involvement in The Implementation of EMS in Ports in Vietnam and Cambodia. J. Clean. Prod. 64: 173-193. doi:10.1016/j.jclepro.2013.07.032.

Mukhtasor. 2007. Pencemaran Pesisir dan Laut. Jakarta: Pradnya Paramita.

Muninggar R, Lubis E, Iskandar BH, Haluan J. 2016. Samudera Nizam Zachman Jakarta Significant Environmental Aspects at Jakarta Nizam Zachman Fishing Port. Marine Fisheries: Jurnal Teknologi dan Manajemen Perikanan Laut. 7: 203-210.

Muninggar R, Lubis E, Iskandar BH, Haluan J. 2017. Water Quality Status in the Largest Indonesian fishingport. AES Bioflux. 9: 173-182.

[OECD] Organization for Economic CoOperation and Development. 2003. OECD Annual Report 2002.

Pemda DKI Jakarta. 2013. Peraturan Gubernur DKI Jakarta No 69 tahun 2013 tentang Baku Mutu Air Limbah Bagi Kegiatan dan/atau Usaha.
Perdana D. 2017. Analisis dan Mitigasi Risiko terhadap Kinerja IPAL Pelabuhan Perikanan Menggunakan Metode Fault Tree Analysis (FTA). Surabaya: Institut Teknologi Surabaya.

[PP] Peraturan Pemerintah Republik Indonesia No 57 Tahun 2015 tentang Sistem Jaminan Mutu dan Keamanan Hasil Perikanan serta Peningkatan Nilai Tambah Produk Hasil Perikanan.

[PPSNZJ] Pelabuhan Perikanan Samudera Nizam Zachman Jakarta. 2017. Laporan Tahunan 2016. Jakarta: PPSNZJ.

Puig M, Wooldridge C, Casal J, Darbra RM. 2015. Tool for The Identification and Assessment of Environmental Aspects in Ports (TEAP). Ocean Coastal Management. 113: 8-17. doi:10.1016/j. ocecoaman.2015.05.007.

[Pusdatin KKP] Pusat Data, Statistik, dan Informasi Kementerian Kelautan dan Perikanan. 2016. Laporan Tahunan 2016 Pusat Data, Statistik, dan Informasi Kementerian Kelautan dan Perikanan. Jakarta: Pusdatin KKP.

Sahubawa L. 2011. Analisis dan Prediksi Beban Pencemaran Limbah Cair Pabrik Pengalengan Ikan. Jurnal Manusia dan Lingkungan. 18(1): 9-18. doi: https://doi.org/10.22146/ jml.18432.

Siahaan EI. 2012. Pengembangan Pelabuhan Berwawasan Lingkungan (Ecoport) Dalam Rangka Pengelolaan Pesisir Terpadu (Studi Kasus Pelabuhan Tanjung Priok) [Disertasi]. Bogor: Institut Pertanian Bogor.

Supriyanto S. 2013. Analisis Pengelolaan Pelabuhan Perikanan Berwawasan Lingkungan di Pelabuhan Perikanan Samudera Nizam Zachman Jakarta. Jurnal Ilmu Lingkungan. 7: 159-179.

[UU] Undang-Undang Republik Indonesia No 13 Tahun 2003 tentang ketenagakerjaan.

[UU] Undang-Undang Republik Indonesia No 26 Tahun 2007 tentang Penataan Ruang.

[UU] Undang-Undang Republik Indonesia No 32 Tahun 2009 tentang Perlindungan dan Pengelolaan Lingkungan Hidup.

[UU] Undang-Undang Republik Indonesia No 45 Tahun 2009 tentang Perubahan atas Undang-Undang Nomor 31 Tahun 2004 tentang Perikanan. 